\title{
Emergency remote teaching during Coronavirus pandemic: the current trend and future directive at Middle East College Oman
}

\author{
Abdalellah O. Mohmmed ${ }^{1}$ [ $\cdot$ Basim A. Khidhir ${ }^{1} \cdot$ Abdul Nazeer $^{1} \cdot$ Vigil J. Vijayan $^{1}$
}

Received: 17 May 2020 / Accepted: 19 June 2020 / Published online: 1 July 2020

(c) Springer Nature Switzerland AG 2020

\begin{abstract}
Due to COVID-19 outbreaks worldwide, the academic institutions have been enforced to entirely cancel face-to-face teaching including laboratories and other learning experiences as a mitigation step against the risk posed by the Coronavirus. Accordingly, various measures by the higher education providers have been initiated to implement social isolation strategies, and online teaching is followed with rapid curriculum transformation. The online delivery is more convenient, as it can provide vibrant and dynamic teaching and learning environment. However, due to time constraint, the curriculum transformation is anticipated to occur rapidly without sufficient preparation. Therefore, in this study, the concept of the emergency remote teaching (ERT) including its application and evaluation is thoroughly discussed. The application of the ERT in the Middle East College Oman has been considered as case study. This study draws on CIPP evaluation model to assess the effectiveness of the adopted model, and qualitative data were collected online taking random samples of students and educators. Besides, interview and questionnaire responses, experiences, beliefs, and challenges encountered by the educators and students on the emergency remote teaching were used and analyzed. In addition, students' weekly attendance segregated with session modes, levels and module nature were considered to evaluate the students' participation to the online classes. The collected information were analyzed, and based on the analysis outcomes, recommendations were forwarded to serve as an input for future strategies and policies and to improve the performance of teaching learning activities during similar circumstances.
\end{abstract}

Keywords Emergency remote teaching · COVID-19 pandemic · CIPP evaluation

\section{Introduction}

On December 31, 2019, a group of 27 pneumonia cases stemming from a mysterious etiology were reported by Wuhan health authority [1]. All of the infected cases were linked to the closed Wuhan Huanan Seafood Wholesale Market. Later medical investigations resolve the ambiguity and determined this pneumonia as novel Coronavirus

Abdalellah O. Mohmmed

abdalellah@mec.edu.om

Basim A. Khidhir

basim@mec.edu.om

Abdul Nazeer

anazeer@mec.edu.om

Vigil J. Vijayan

vigil@mec.edu.om

1 Department of Mechanical Engineering, Middle East College, Knowledge Oasis Muscat, Al Rusayl, Muscat, Oman
(2019-nCoV) or (COVID-19). Then, World Health Organization (WHO) declared COVID-19 as "public health emergency of international concern" through the Health Regulations Emergency Committee. A month later, on January 30, 2020, WHO declared COVID-19 as pandemic [2]. Up to this moment June 11, 2020, COVID-19 has spread to more than 212 countries or territories internationally, including the entire continents, with over 7,451,532 cases and 418,872 deaths (5.62\% mortality rate). Figure 1 illustrates the graphical distribution of COVID-19 worldwide which indicates that the highest confirmed cases reported in north and south Americas. The top ten countries in terms of the reported cases are: United State of America, Spain, Italy, France, Germany, UK, China, Iran, Turkey, and Belgium [3].The rapid outbreaks of the virus have shed the light globally on the true threat that the virus possesses. While speculation and uncertainty still exist around the virus, heretofore, there are no specific vaccines or treatments for COVID-19 [4]. Therefore, the entire organizations worldwide have begun to explore contingency preparedness plan and percussions to 


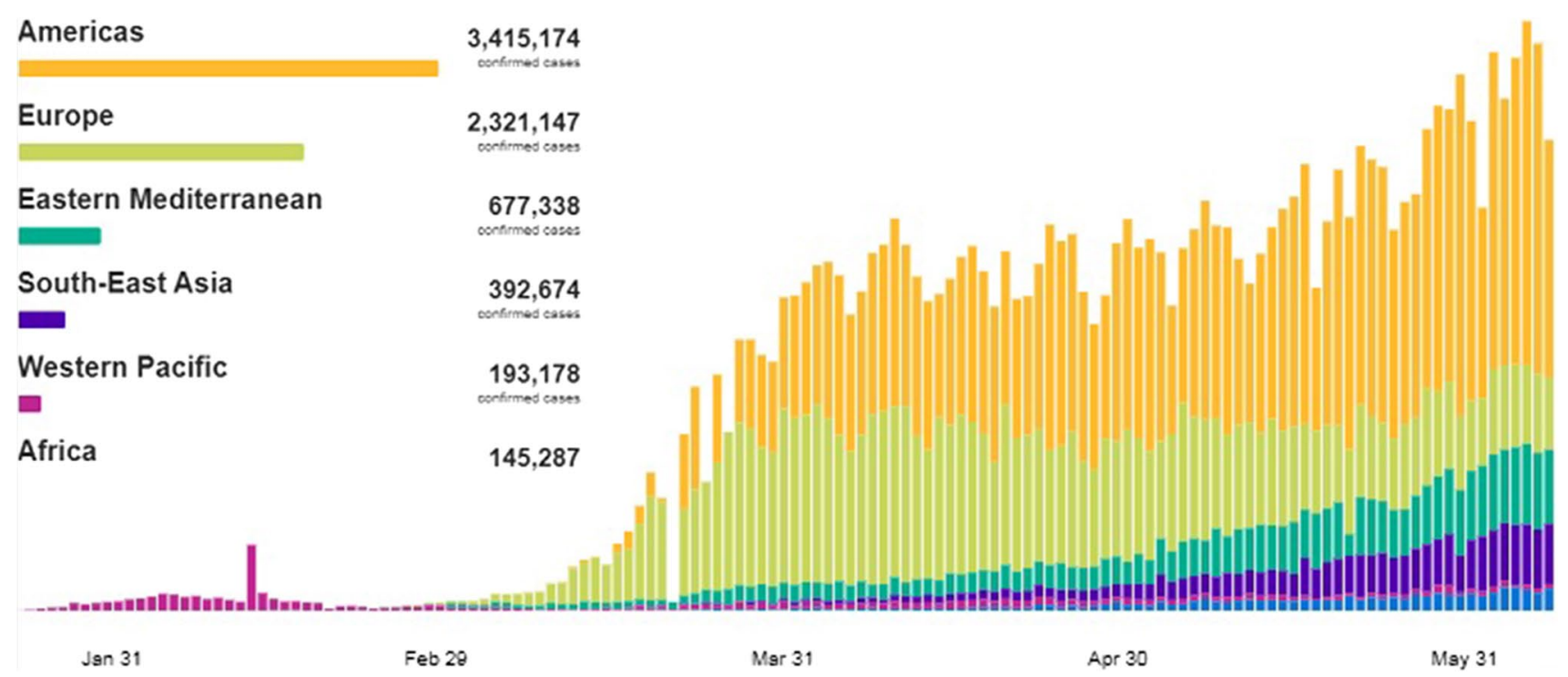

Fig. 1 Confirmed cases over the WHO regions worldwide [6]

confront COVID-19 pandemic. The global higher education sector as the other industrial sectors has extremely affected by the COVID-19 pandemic. Abundant measures have been adopted by governments to restrain the extremely pathogen contagious of COVID-19, and these measures beset the education systems worldwide. Quarantine, self-isolation, lockdown, curfew, and the subsequent closure of the academic universities and institutions have influenced the normal progress of the educational process. On April 6, 2020, 188 countries have enforced interim closure for their educational institutions as reported by UNESCO, while localized closures have implemented by several countries, which consequently affecting 1,576,021,818 learners. Accordingly, as an emergency response to COVID-19, sudden online transformations for the classes at all levels have been argued by most of the educational authorities. However, the issue of the affected groups is how to meet the essential necessary conditions of the remote learning [5].

COVID-19 has immense influence on the academic institutions who relied on the income from this international students [7]. However, the global trend has moved toward "suspending classes without stop learning" which is a contiguous policy launched by the ministry of education in China [8]. As the spread of the disease evolved globally, most of the academic institutions, universities, and schools responded in diverse approaches. Accordingly, the curriculums were converted to an online environment by the educators, with the assistance of digital tools and educational Web sites. The key focus is to convert the curriculum to an online environment rather than focusing on online pedagogy. Overall, this transition process is real test for the organizational agility [9]. However, major challenges unfolded with alternate online delivery mode, especially those related to rapid digitalization of curriculum [10]. While the eternal question, is the higher education sector is well prepared for the upcoming digital era [11]?

Emergency remote teaching is defined as a sudden interim shift of instructional delivery to an online delivery mode as result of an immense catastrophe, in contrary to the online courses which are initially planned and designed to be delivered virtually [12]. ERT comprises ultimate exploitation of the available remote teaching tools for delivering the curriculum or educational materials that would normally be delivered physically or as hybrid or blended courses. Once the disaster or catastrophe circumstances abate, the instructional delivery will revert to its original format. Thus, due to urgency and utmost priority, providing a reliable, temporary, fast, and durable access to the instruction and instructional assistances during the crisis would be more efficient than reconstruct a sophisticated educational ecosystem. Considering the aforementioned differences, distinguishing between the ERT and the online learning concepts became uncomplicated task. In a time of previous crisis, several models were implemented by various countries in a response to schools and universities closures such as radio, televisions, and mobile learning. For instance, radio and DVDS were used in Afghanistan to expand the education accessing where it was interrupted and suspended due to conflict and violence [13]. Also, an interactive Web-based program was developed to provide a variety of methods of student-centered learning process, as well as to mitigate the effects of frequent schools closure in Palestine [14]. Moreover, the utilization of the Educational Technology (EdTech) in response to the displacement during the Syrian Conflict [15], however, with 
the existent digital revolution, abundant tools, and options will be available to ease the transformation process of the emergency remote teaching. Therefore, the educators and academic institutions have to prepare themselves with the requisite skills and tools in a fast manner to this shift. But, the lack of sophisticated technology and experience in developing an online learning platforms is the main challenge that faced educators and academic institutions worldwide. Moreover, according to the International Telecommunication Union (2019), although 93\% of the world's population lives within covered Internet zones, about 53\% only utilizes the Internet which is considered as an ancillary obstacle facing the continuity of the educational process [16]. Other form of the online media like television or radio can be used to reach learners those who do not have Internet access. However, using the mass media required adequate time for planning and production which contradict with the concept of ERT as the time is matter. Parallel to that, a suitable environment and atmosphere are required by the remote teaching for efficient delivery process. Living spaces and the family situations are ancillary stress factors which affect the education quality and consequently frustrate both learners and educators [5].

This stay aims to introduce the adopted ERT model at mechanical engineering department Middle East College, Oman, after the cancellation of the physical classes due to COVID-19 outbreaks. The adopted ERT model was evaluated using CIPP model of evaluation in terms of context, input, process, and product output. Qualitative data were collected though online tools taking random samples of students and educators. Besides, interview and questionnaire responses, experiences, beliefs, and challenges encountered by the educators and students on the emergency remote teaching were used and analyzed.

\section{Transformation to emergency remote teaching}

In this study, the process of shifting the instructional delivery mode from face-to-face to ERT at Middle East College Oman is considered as a case study. Middle East College (MEC) is one of the leading higher education institutions in the Sultanate of Oman accredited by Oman Academic Accreditation Authority (OAAA). The college is home to over 4500 students from the region and around the world. Located in the Knowledge Oasis Muscat, the college offers undergraduate and postgraduate programs in different areas of Engineering, Business, Technology, and Logistics Management in academic partnership with Coventry University, UK, and Breda University of Applied Sciences, Netherlands [17]. The transformation process has been accomplished through two phases, namely curriculum transformation and staff development which they executed simultaneously.

\section{Phase 1: curriculum transformation}

Online lectures based on a wide range of information technology equipment raised serious challenges. Teachers who used to teach live classes will need to engage in novel methods to achieve effective teaching outcomes, which may affect the quality of tertiary education. Besides, students in remote and rural areas may not have the network capacity, thereby leading to a loss in educational opportunities. In addition, teachers who provide classes on taped broadcast network may face problems of copyright in disseminating the information [18]. Table 1 illustrates the pros and cons of various instructional delivery methods which are widely used in the education field. However, during the existent critical period of COVID-19, a compromise model that involves the major benefits and eliminates the drawbacks of these teaching delivery methods is extremely needed. Therefore, at MEC, a specific transformation frame work was designed to overcome these challenges and ensure the stability of the education process.

Figure 2 illustrates the transformation process model to ERT at MEC. Forming the model in this circular shape will permit the students to obtain the information and penetrate the cycle from any point without missing the information. Intuitively, the instructional delivery starts from the online lecture which can be conducted utilizing the available platforms (MS Team and MS Lecture Note). Through these online lectures, detailed explanation about the topic is given and the students will get the opportunities to raise their doubts about the relevant issues to the topic or overall module. Meantime, these online lectures are recorded and shared to the students on the college platform (Moodle) and on the social media (MS Kaizala). The recorded lectures will grant the students who face Internet connections disturbance or limited bandwidth a second follow-up chance. However, in some cases, downloading the complete lecture will remain as an eternal issue due to availability of the Internet quota/data. Thus, Voice over PowerPoint slides was used to provide concise hints about the lecture at each slide. The key benefit of this method is that the file size is small which acquires a minimal Internet requirements. In contrast, the lecture time is flexible and dynamic to suit the educators and learners times, and the social media play a major role in fixing the lecture times. As the module leader contacts the students through (MS Kaizala) a day before the class to fix the class time, then the class will be scheduled according to the student's availability. 


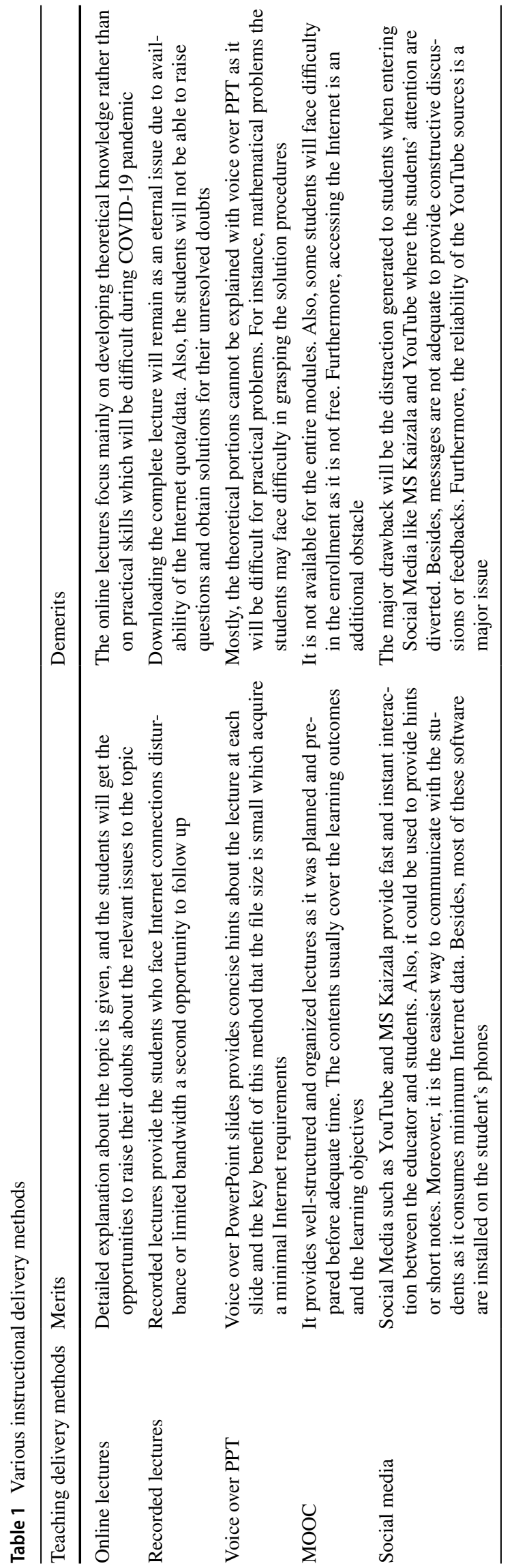

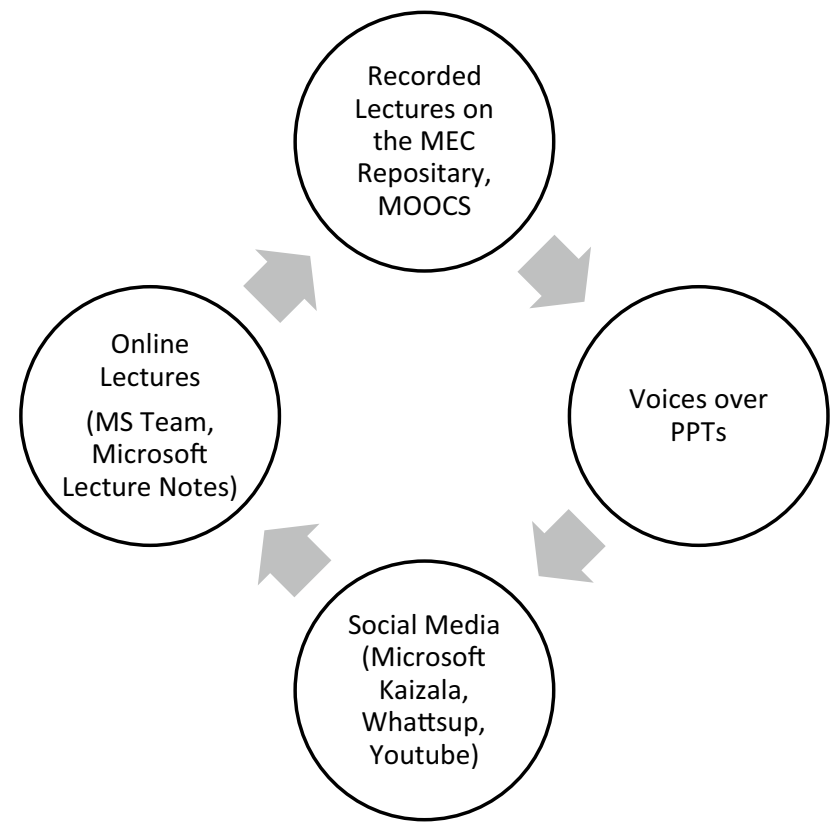

Fig. 2 Transformation process model to ERT at MEC

\section{Phase 2: staff development}

Middle East College established a staff development program more than 10 years ago through the work of its Instructional Development Unit, later renamed as the Centre of Academic Practice (CAP). CAP is responsible from providing the right platforms, workshops, and programs to foster the academic and administrative practice at MEC. After the outbreak of COVID-19 and the suspension of the face-toface classes, CAP established a massive program for the academic staffs about the utilization of the online tools on the instructional delivery. The aims of this program are to support the educators during the transformation process to the ERT at the college. Examples of the conducted workshops and webinars are tabulated in Table 2. Evaluations and feedbacks of these workshops are collected by the CAP department through various online platforms such as special designated survey and Google forms.

\section{Evaluation of emergency remote teaching}

A quality evaluation of ERT at Mechanical Engineering department in Middle East College OMAN is particularly considered to evaluate the quality of remote teaching at MEC. The study was conducted through data analysis of online classes for 4 weeks based on students and educators experience. Both synchronous and asynchronous learning modes adopted were considered. Synchronous learning is a well-structured learning strategy, where the courses are 
Table 2 Organized workshops and webinars by CAP to support ERT at MEC

\begin{tabular}{|c|c|c|c|c|}
\hline Organizer & Workshop title & Date & Durations (h) & No. attendees \\
\hline CAP & Webinar-creating great learning experiences & $07 / 04 / 20$ & 1:00 & 16 \\
\hline CAP & Webinar-assessing students online & $01 / 04 / 20$ & $1: 00$ & 28 \\
\hline CAP & Webinar-supporting your students online on their assessment & $02 / 04 / 20$ & $1: 00$ & 8 \\
\hline CAP & Webinar-generic questions about teaching online & $02 / 04 / 20$ & 1:00 & 18 \\
\hline CAP & Education on Digital and Social Media (MS Kaizala) & $03 / 04 / 20$ & $1: 00$ & 8 \\
\hline CAP & Use of Microsoft Class Notebook for online education & $06 / 04 / 20$ & $1: 00$ & 21 \\
\hline CAP & An introduction to emergency planning and prepared & $08 / 04 / 20$ & $1: 00$ & 35 \\
\hline CAP & Collaborative class room with MS Teams & $13 / 04 / 20$ & 1:00 & 22 \\
\hline CAP & Online marking and moderation & $02 / 06 / 20$ & 1:00 & 50 \\
\hline CAP & Online evaluation/marking and feedback workshop & $11 / 05 / 20$ & 2:00 & 117 \\
\hline
\end{tabular}

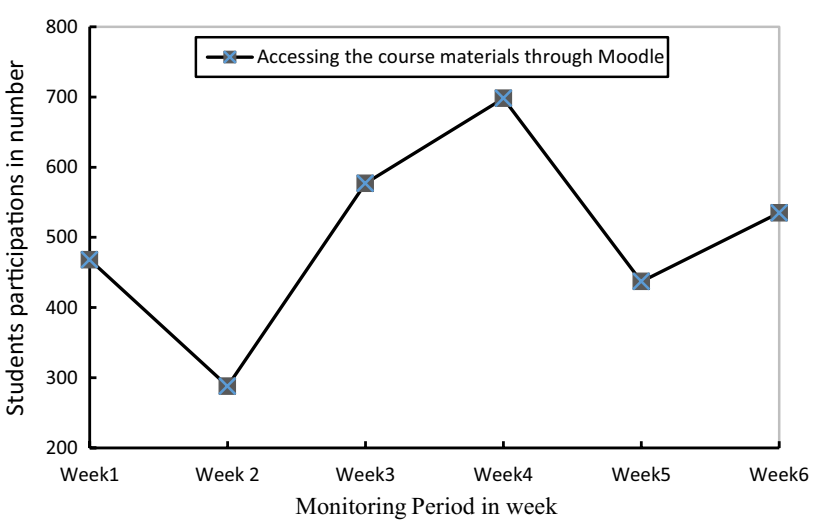

Fig. 3 Student interaction with Moodle platform for a period of 6 weeks

scheduled at specific times on virtual classroom settings which were carried out through MS Team and Moodle platform, whereas asynchronous learning, the courses are not scheduled on live virtual classroom settings, but apart from scheduled class time is discussed and explained using social networking tool (MS Kaizala) to communicate students and teachers. Figure 3 illustrates the student's interaction with the Moodle platform for a period of 6 weeks during the COVID-19 period. In which, the highest number of logs were recorded at week 4 which is close to the submission of first assessments.

While Fig. 4a, b illustrate the student interaction and participation with the synchronous and asynchronous modes of the adopted ERT model, from Fig. 4, the interaction of the students during the schedule online sessions was observed higher than messages and unscheduled discussions. Generally, it was observed that the synchronous mode is more effective than the asynchronous mode. Besides, the MS Kaizala was used by students to obtain further clarifications about their unresolved doubts.

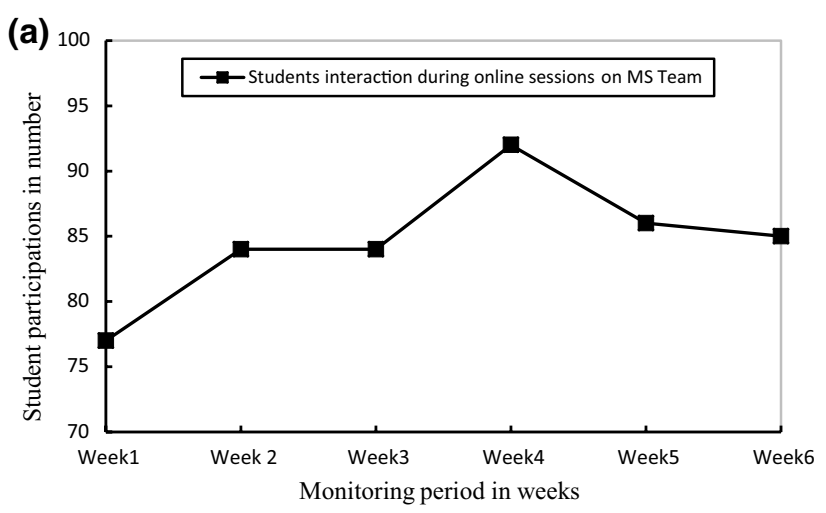

(b)

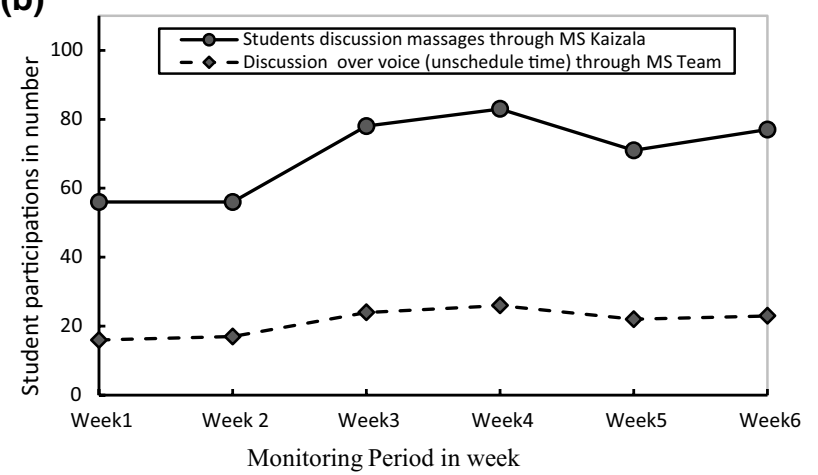

Fig. 4 Monitoring the students participation and interactions with the adopted modes a synchronous, $\mathbf{b}$ asynchronous

\section{Context evaluation}

According to [19], context evaluation is defined as assessment of the needs, problems, opportunities, and problems which can be addressed in a particular environment. For the current study, the context was evaluated using document analysis from the data collected for 4 weeks duration, the main objective is to continue the teaching and learning process during COVID-19 through ERT mode. The conducted study was focused on student attendance, students 
interaction, type of students (full-time and part-time), technical input, and educators feedback. Several difficulties were observed during the transformation or shifting process to virtual education through the adopted ERT model. These difficulties could be attributed to several factors, which are:

- In a short interval of time, redesigning the modules to suit the online platform is challenging and tedious task.

- It is difficult for faculties and students to adapt the new teaching and learning environment.

- Lack of focus during the online teaching due to the absence of eye contact, gesture, and class room atmosphere.

- Home atmosphere is not suitable for teaching and learning process.

- Students living in the remote areas are facing difficulties in accessing the online platforms, and this problem is also highlighted by [20].

However, with all these hurdles, the adopted ERT encompasses several merits for both teachers and students

- Student can view the recorded sessions several times, and the frequent access to the resources provides ancillary opportunities for the students to consolidate their knowledge.

- This new teaching environment allows the students to become self-learner or students lead learning.

- As the key focus is directed toward curriculum redesign, the modern prepared curriculum will be ready for any sudden shift in the future. Besides, the faculties acquired new skills and experience to adapt similar situations.

- Transformation from conventional teaching to online teaching bridge the gap between the conventional and recent advanced technologies for both teachers and students.

The results were based on interview statistics and document analysis which illustrates various modules, assessments, students (full-time and part-time), and technical difficulties. Further, student's responses show that the adopted ERT model in MEC is supportive. Besides, the educators were also satisfied with the performance of the adopted model.

\section{Input evaluation}

Input evaluation to provide information about the sources can be used to implement ERT during COVID 19, and the basic requirements are classified into three categories:

1. Hardware Resources: (Laptop/computer + Internet access).
2. Software Resources: (Web-based tools and applications include real-time chatting, video lecture, presentation, and social networking).

3. Learning Resources: (Module content resources, access to library content, massive open online courses, etc.).

In order to evaluate the efficiency of ERT, student's response was collected regarding the adopted tool (Microsoft Team), also the impact of social networking tool MS Kaizala, Web-based platform for uploading material and assessing the assignment (Moodle), along with the educator's responses.

Response from educator 1 MS Team has performed well, students and educators are satisfied with MS Team interaction tool, and the lecture was recorded. Students were extremely satisfied with Kaizala tool as several students were obtaining immediate responses, besides, Kaizala ease the process of access and communication. Moodle platform was successfully used for uploading materials and assignments.

Response from educator 2 Microsoft Teams is a very useful tool to handle online classes. Students were satisfied with Online Session. The lecture is recorded, and the link is shared to the students through Kaizala, and voice over PowerPoints slides was recorded and the slides uploaded in MOODLE, which can be accessible at any time.

Response from educator 3 Microsoft team's Whiteboard was used extensively in explaining the problems which help students to understand the fundamental theories. Students used to communicate through Kaizala for any doubts. The online class recorded and uploaded to MOODLE.

In general, the response of adopted tool (MS team) was excellent, and a tool used for asynchronies learning (MS Kaizala) is efficient and has few technical issues, especially, in the remote areas where the Internet connection is poor. The majority of teachers responded that the training courses provided by the college have assisted them to adapt the shifting process to ERT and rapidly adopt a teaching methodology which can suit the current technology. Besides, most of the students were satisfied with the utilized tools and the adopted ERT model by the MEC College. Particularly, about the voice over PowerPoint slides, recorded video class, and MS Kaizala communication.

\section{Process evaluation}

Process evaluation requires a systematic approach to achieve quality teaching and learning process, and the evaluation is usually conducted based on type module and topics presentation, research papers, team projects, peer assessments, 
and standardized tests (e.g., multiple choices) [21]. In the present study, qualitative academic supervision process evaluation was conducted with the assistance of Web-based platform Moodle where certain task with specific deadline was assigned. Then, students can upload their work as evidence. Furthermore, with student's interaction through MS team and MS Kaizala, an online time-limited Quiz through Mentimeter or Socrative was used to provide formative and summative assignments. Student progress was recorded and discussed on daily basis to retain the entire students online and to achieve the targeted module objective. By the end of online session, the educator discussed the issues related to the delivered lesson along with the other associated ERT issues. Considering the student's feedback, the whole educators used to discuss and fetch for the potential alternatives, and those may enhance the ERT efficiency.

It was observed that the student's responses were varied according to the module and assessments types. Positive responses were observed for the modules with experimental laboratory, simulation laboratory, and modules which has assignments comprising open book test and projects, while negative responses were realized for the modules with end semester exams. On the contrary, absentee's percentage for the full-time students are higher than part-time students. Conclusively, student's feedbacks reported that the adopted ERT model is supportive, convenient, and appropriate for this critical period. This ERT model provides immense flexibility level to the students, as the student may watch the recorded sessions from Moodle or Kaizala platforms at their own suitable time. It is worth mentioning that the Analysis may vary depending on the students or college and department. However, the analysis conducted in this study was formulated based on the subsequent assumptions.

- All students have proper facilities (Laptop, Internet access, software's, etc.)

- All students are available at defined time of class.

- All students have similar atmosphere of class.

- No service or technical issue interruption.

- All students and family are healthy (No medical issue).

Furthermore, the analysis is based on data collected for a period of four weeks. The data are collected after shifting the physical classes to online classes through the developed ERT model.

\section{Analysis based on student modes}

Two session modes are available in MEC which are full-time and part-time. (level 0 ) has only one module with full-time students, obtained feedback is satisfying, and low percentage of student's attendance of $50 \%$ was observed, while six modules are offered in (level 1) for both full-time and part-time sessions. Scrutinizing of the collected data demonstrates that the variation in student attendance is insignificant; however, the student attendance for full-time student is $5 \%$ higher than part-time students. Furthermore, six modules are offered in (level 2) for both full-time and part-time students, and it was observed that the student attendance for part-time student is $13 \%$ higher than full-time students. Similar observation was obtained for (level 3) modules; however, students attendance for part-time students are $16 \%$ higher than full-time students. It is worth mentioning that the outcomes of the collected data are provisional which may vary due to different scenario, nature of students, type of college/universities, geographical region, or even with the semester progress.

\section{Analysis based on module's assessment}

For (level 0), the data collected for one module only and student's response were $50 \%$. While for (level 1), the collected data demonstrated that the number of students attending the modules those have a laboratory and end semester exams is higher by $30.6 \%$ than modules those does not have end semester exams, which illustrates the nature of modules and assessments play a major role in student's attendance, involvement, eagerness, and interest. By contrast, for the (level 2) modules, the student's presence was $22.6 \%$ higher for the modules with laboratory assessment only than modules that involve laboratory and exams, whereas a slight variation of $9 \%$ was observed for the modules those does not have any practical (laboratory) assessments. Moreover, for modules those assessed through exams and presentations at (level 3), the absenteeism rate was less by $34.9 \%$ in comparison with the modules those have laboratory assessment, while for the modules with written assignments only, the student's presence was less by $55.57 \%$ than the modules having exams and presentations. Therefore, from the above comparisons, it is obvious that the students are interested and eager to attend the modules those having exams and presentations.

\section{Analysis based on student's levels}

Considering students attendance data along with educator's feedback, it was noticed that the absenteeism rate decreases with increasing the student/module level. This was attributed to the student maturity and responsibility. Besides, affirmative responses regarding the adopted ERT model were obtained from the students at (levels 2 and 3 ). While a minimum level of interactions to the adopted tools was observed for the students at (level 0). Besides, the statics illustrates that a higher variation of $53 \%$ is observed between (level 3) and (level 0) students in terms of response and interaction to ERT, whereas the comparison for (level 1) and (level 2) exhibited a variation of $21 \%$ 
and $11 \%$, respectively, compared with (level 3) students. It is worth mentioning that these analyses were conducted based on data monitoring for 4 weeks, which reflects the trend after the suspension of the physical classes immediately and the first impression about the ERT strategies in the mechanical department. Although the trend may vary with the semester progression, but the responses from the module leaders support the existent trend which is the students at advance semesters have immense interest toward the adopted ERT model in comparison with the junior students. Figure $5 \mathrm{a}-\mathrm{c}$ illustrates the attendance comparisons between the full-time and part-time students from (level 1) to (level 3).
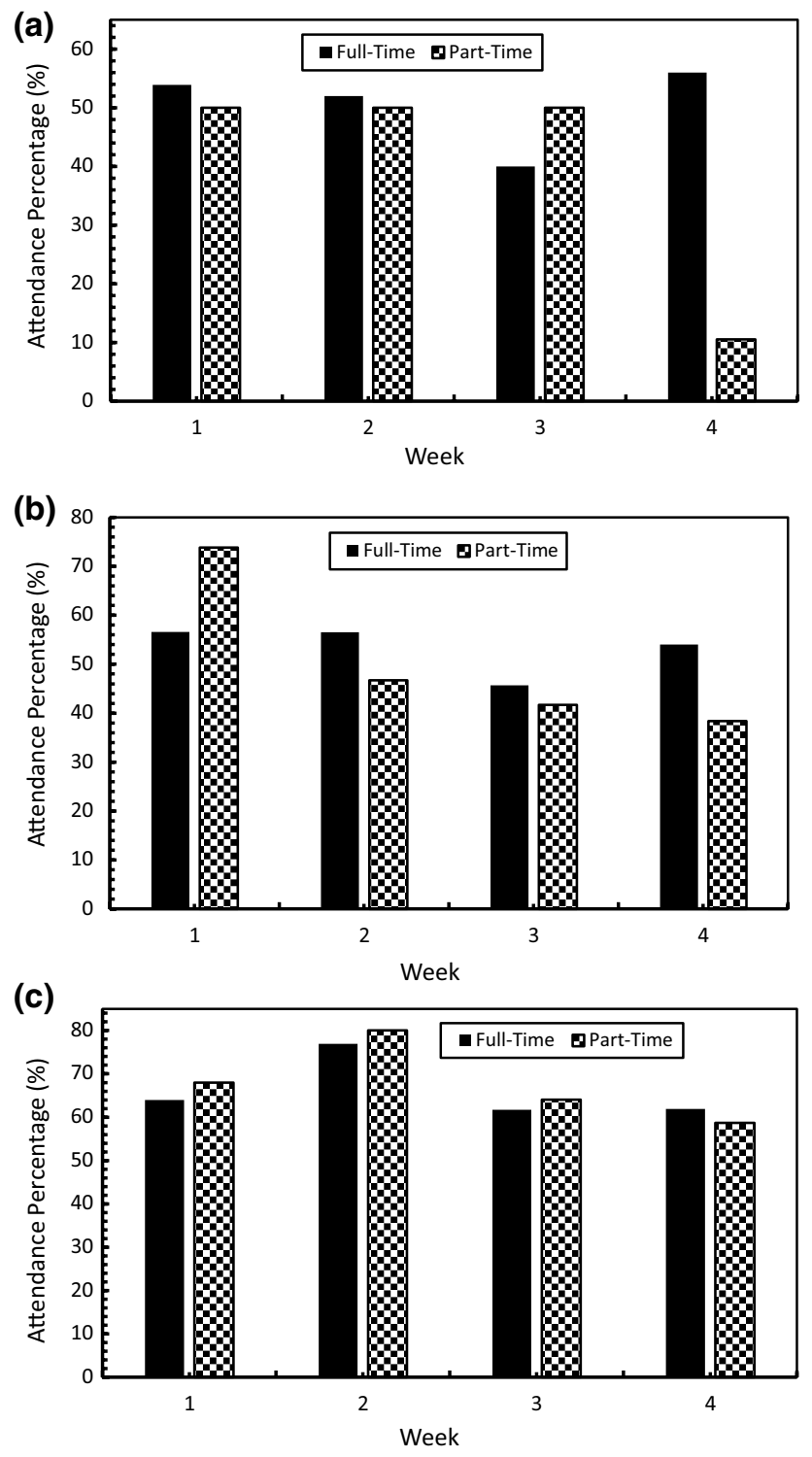

Fig. 5 Weekly attendance monitoring for full-time and part-time students for a level 1, b level 2, c level 3

\section{Product evaluation}

A product evaluation assesses outcomes of adopted technique which will assist us to mitigate the drawbacks of adopted model in future such the effectiveness deficiency, besides, focuses on the fulfillment (or not) of objectives [19]. Cornock [22] mentioned that the product evaluation for the ERT is not important. In addition, as the shifting to the ERT is usually occurred with staggering speed in short time, the ERT evaluation should focus on the context, input, and process rather than product (learning) [12], which interpret that few institutions are changing their grading system from letters to fail/pass during the period of ERT [23]. In this study, the product evaluation of the ERT model in the mechanical engineering department (MEC) was conducted. This evaluation aims to assess the impact of ERT on student's interaction and measure whether the pre-defined objectives of the adopted ERT model were achieved or not. The outcomes of this analysis demonstrated that the majority of students appreciate the devoted efforts to implement ERT without suspending the teaching and learning process during COVID-19 pandemic. Although online teaching and learning are not as efficient as the physical class room and campus atmosphere, the adopted ERT model successfully facilitated the teaching and learning process according to the students and educators responses. On the other hand, although of the disturbance occurred during this critical period of COVID-19 pandemic, there are several important spinoffs that have been emerged despite of the crisis. Firstly, ERT provides a substantial opportunity for students to become a self-learners and convergent thinker. Secondly, it fosters the skills of students and teachers in dealing with modern technologies and enables to exploit the social networking tools. Thirdly, ERT provides excellent opportunity for the teacher to develop their skills through various teaching and learning strategies that will have immense impact on the students' skills, attitudes during future emergencies.

\section{The challenges behind the implemented ERT model}

Prior to the impact of the pandemic, students and educators were socializing online (not necessarily together), they have their own personal learning spaces which may be formal or informal, ways of seeking content to meet short-term learning needs, and they have their own choice of equipment, tools, applications, and preferences of communication. With the emergence of ERT around the world in Higher Education Sector due to COVID-19, severe challenges emerged which can be accessed along three perspectives: educator, students, and contents. The educators should be equipped with the necessary tools required for the efficient method of 
ERT. They should attain the pedagogic creativity to engage the learners and importantly to stimulate them in learning. Meanwhile, they should also focus on the technical skills for ERT. The educators will spend their fruitful times in platforming a series of learning activities using the thousands of freely available learning resources (YouTube, FutureLearn, OpenLearn, Open Educational Resources, etc.) and providing plain support to students instead of just delivering the best lectures. Hence, the higher authorities in charge should prioritize in communication and dialogue for learning, not just transmission of content through online. The onus of the assessment lays down on the module leader as they have to assess the students as individuals and groups covering the necessary outcomes as required for the study as compared to a previously arranged assessments.

For the students, they should have the necessary learning skills, capacity for independent learning, effectiveness to communicate efficiently, oppugn themselves, and seek for guidance when required. By online learning, the students should attain an ability to converse and interact with another person where most of the students face with the conventional method of teaching. The students should also adapt with the new assessment strategy as proposed by the module leader which is for their own beneficial. While the contents should be promptly procurable and should be in a standard format that is reachable to the learners, it should be a proper medium and should prompt them for self-study with proper guidance wherever possible [22]. The usage of a wide range of information technology for online education raised many serious challenges for the educators. The earlier live session on campus classes which was aligned with the learning and program outcomes of the courses has to be shifted with new methods to achieve the effective teaching outcomes, which in a way may affect the teaching outcomes and the quality [18]. Besides, the educators and students will find difficult problems while engaging in online teaching and learning sessions at home. The distractions may be in the form of burden of homework or childcare which may have dissenting impact on the online learning and teaching process. Obtaining a suitable work space for learning and teaching due to difficult family backgrounds will hinder the education process [8].

The implemented ERT model in the Middle East College (MEC) had great responses from the both sides of educators and students; however, there are several challenges that should be highlighted and accessed. The module leader contacts the students for the respective modules through the official platform of Microsoft Outlook, messaging in MS Teams and MOODLE and in social media platforms as Microsoft Kaizala to engage them to the online lecture class. But still there a gap exists, which a few students will not respond to these messages. Lack of responses are due to several reasons such as less access to Internet resources or other personal matters. In addition, another crucial factor for the instructor is to obtain the concentration and attention of the students during the online sessions. But in a digital platform, there are chances that the students are distracted to other activities like Web browsing during the online session without the knowledge of the instructors, unlike the case in physical live classes. Furthermore, the module leaders have to achieve the learning outcomes of the modules which comprise laboratory sessions or industrial field visits. Although these activities were canceled due to existent circumstance, still they need to be assessed through innovative online activities. For instance, in the Mechanical Engineering department there are modules like Solid Mechanics 2, Materials and Manufacturing, etc., which encompass practical experiments in the laboratory. Besides, there are modules like Mechanical Product Innovation and Management, in which the students has to visit an industry and provide a comprehensive product study. In these cases, the competent authorities or module leaders have to align the online learning for these respective modules to achieve the learning outcomes as that of the laboratories or visits.

On the other hand, the students in Mechanical Engineering department at MEC are from diverse locations of Oman. There are students from rural areas or villages that have limited Internet access. Hence, those students are traveling a certain distance to access the Internet and attend the online sessions. Although the adopted ERT model eliminates this by recording these sessions on various platforms, but still the students seek for online interaction as they may have some doubts to clarify. Also, in the campus, there are part-time students who are specifically classified as Students Working Outside Muscat (SWOM). Those students attend the class for 2 weeks per month as they have to work in the deserts for the rest 2 weeks. Due to lockdown in Muscat (from March 2020), their shift was changed to 1 month in home and other in the desert. The nature of their work summoned that the worker should stay on duty for $12 \mathrm{~h}$ which restrict their availabilities for the online interaction session. Therefore, those students are merely relied on the recorded sessions along with direct communication with instructors on other platforms. Moreover, when the ERT has been established, the Peer Tutoring sessions which is one of the foremost teaching methods followed by MEC has been hindered due to the availability of the peer tutors.

Conclusively, all the contents available online should be aligned with the learning outcomes of the respective modules. The learning materials prepared by the educators has to be accessible by all the students. But this may not be possible due to the lack of Internet resources in deserts and rural villages. Laboratory sessions are not available through virtual sessions of ERT for all the entire modules which affect the student's practical skills. Similar scenario exists 
for industrial visits and case studies as of the current technology, and virtual industries are not available.

\section{Conclusion}

The abrupt migration to online learning due to COVID19 pandemic has created an extreme disruptions for the students, educators, and managing staff. This disruption emerged and extended to their normal lives outside the academic institutions and university. Therefore, the entire shifting process to the ERT must be conducted with the consideration that this moves toward the continuity of the education might not be a priority to the involved stakeholders. Asynchronous activities are more rational than synchronous as it provides an ancillary opportunities to the students whom failed to attend the immediate sessions. Furthermore, flexibility for assignments due dates within modules, department policies, and overall institutional policies should be considered.

Non-determined policy [24] has guided the entire concerned about the current challenging circumstances arising from COVID-19. These concern such as the factors that affect students' preparation and performance along with the factors of teaching and learning activities. Therefore, there is a necessity to incorporate an alternate approach such as ERT approach to ensure that students are thoroughly supported with these new challenges. Besides, smooth transition to online sessions with a continuous monitoring of the ERT progress and issues is also recommended. Moreover, prompt responses to the feedbacks and inquiries are required to eliminate the issues. On the contrary, "doing no harm" policy which borrowed from the health sector [25] has been incorporated as a measure for COVID-19. In this policy, the entire suggested plans and measures by policymakers during this critical time ensured that do not harm the academic stakeholders, and the whole learners reap benefits from the suggested measures [5]. According to these concerns, a general consensus was built to proceed further with supporting the students through the adopted ERT model in MEC and revised the assessments [26].

Acknowledgements The authors would like to acknowledge the financial and logistic support from Middle East College, Oman. Also, the authors would like to thanks Dr. Fiseha Guangul for editing and reviewing the draft. Special thanks to the College's Dean, Associate Dean of Academic Affair, and CAP department for their continuous support.

\section{References}

1. Committee W.C.H. (2019) Wuhan Municipal Health and Health Commission's briefing on the current pneumonia epidemic situation in our city 2019
2. Liguori E, Winkler C (2020) From offline to online: challenges and opportunities for entrepreneurship education following the COVID-19 pandemic. Sage, Los Angeles

3. Organization W.H. (2020) Director-General's remarks at the media briefing on 2019-nCoV on 11 February 2020

4. Sohrabi C et al (2020) World Health Organization declares global emergency: a review of the 2019 novel Coronavirus (COVID-19). Int J Surg 76(5):71-76

5. Eder R (2020) The remoteness of remote learning. J Interdisc Stud Educ 9(1):168-171

6. Organization W.H. (2020) Coronavirus disease (COVID-19) situation dashboard. World Health Organization website. https ://who.sprinklr.com/. Accessed April 2020. 17

7. Perrotta C (2020) Coronavirus quarantine could spark an online learning boom. The Conversation. https://theconversation .com/coronavirus-quarantine-could-sparkan-online-learningboom-132180. Accessed 23 Mar 2020

8. Zhang W et al (2020) Suspending classes without stopping learning: China's Education Emergency Management Policy in the COVID-19 Outbreak. Multidisciplinary Digital Publishing Institute

9. Wu Z (2020) How a top Chinese University is responding to coronavirus. https://www.weforum.org/agenda/2020/03/coron avirus-china-the-challenges-of-online-learning-foruniversities 1. Accessed 23 Mar 2020

10. Crawford J et al (2020) COVID-19: 20 countries' higher education intra-period digital pedagogy responses. J Appl Learn Teach 3(1):9-28

11. Houlden S, Veletsianos G (2020) Coronavirus pushes universities to switch to online classes-but are they ready. The Conversation. https://theconversation.com/coronaviruspushes-unive rsities-to-switch-to-online-classes-but-arethey-ready-13272 8. Accessed 23 Mar 2020

12. Hodges C, Moore S, Lockee B, Trust T, Bond A (2020) The difference between emergency remote teaching and online learning. EDUCAUSE Rev. https://er.educause.edu/articles/2020/3/ the-difference-between-emergency-remote-teachingand-onlin e-learning. Accessed 23 Mar 2020

13. Davies L, Bentrovato D (2011) Understanding education's role in fragility: synthesis of four situational analyses of education and fragility: Afghanistan, Bosnia and Herzegovina, Cambodia, Liberia. 2011, IIEP research papers. International Institute for Educational Planning, Paris

14. Shraim K, Khlaif Z (2010) An e-learning approach to secondary education in Palestine: opportunities and challenges. Inf Technol Dev 16(3):159-173

15. Tauson M, Stannard L (2018) EdTech for learning in emergencies and displaced settings: a rigorous review and narrative synthesis. Save The Children, London. https://resourcecentre.savet hechildren.net/node/13238/pdf/edtech-learning.pdf. Accessed 2 Apr 2020

16. Union, I.T. (2019) Measuring digital development Facts and figures 2019. International Telecommunication Union, Geneva

17. Middle East College O (2020) April 2020 [cited April 2020]. https://mec.edu.om/en/About-MEC

18. Wang $C$ et al (2020) Risk management of COVID-19 by universities in China. J Risk Finan Manag 13(2):36

19. Stufflebeam DL, Coryn CL (2014) Evaluation theory, models, and applications, vol 50. Wiley, New York

20. Reich J et al (2020) Remote learning guidance from state education agencies during the Covid-19 pandemic: a first look. EdArXiv 2020. https://doi.org/10.35542/osf.io/437e2

21. Aziz S, Mahmood M, Rehman Z (2018) Implementation of CIPP model for quality evaluation at school level: a case study. J Educ Educ Dev 5(1):189-206 
22. Cornock M (2020) Scaling up online learning during the coronavirus (Covid-19) pandemic. https://mattcornock.co.uk/technology -enhanced-learning/scaling-up-online-learning-during-the-coron avirus-covid-19-pandemic/. Accessed 23 Mar 2020

23. Stanger A (2020) Make All Courses Pass/Fail Now. March 19. https://www.chronicle.com/article/Make-All-Courses-Pass-FailNow/248281. Accessed 10 Apr 2020

24. MEC (2020) Supportive measures and assessment approach for Spring and Summer 2020: Middle East College. http://portal.mec. edu.om/cov19. Accessed 15 Apr 2020
25. Vogus TJ, Sutcliffe KM, Weick KE (2010) Doing no harm: enabling, enacting, and elaborating a culture of safety in health care. Acad Manag Perspect 24(4):60-77

26. MEC (2020) Alternative/Revised Assessment Preparation Guide for Spring and Summer 2020: Middle East College. http://porta 1.mec.edu.om/cov19. Accessed 15 Apr 2020 